\title{
Nurses' and midwives' perspectives on how the crave for the 'perfect' body image affect their own breastfeeding practices: A qualitative study in Ghana
}

\author{
Angela Kwartemaa Acheampong \\ Wisconsin International University College Ghana
}

ALHASSAN SIBDOW ABUKARI ( $\nabla$ alhassan.sibdow@wiuc-ghana.edu.gh )

Wisconsin International University College Ghana https://orcid.org/0000-0002-7530-6501

\section{Research}

Keywords: Nurses and midwives, breastfeeding, body image and breastfeeding, body image concerns, Ghana, sociocultural pressures and breastfeeding

Posted Date: February 23rd, 2021

DOl: https://doi.org/10.21203/rs.3.rs-239038/v1

License: (c) (1) This work is licensed under a Creative Commons Attribution 4.0 International License. Read Full License 
Nurses' and midwives' perspectives on how the crave for the 'perfect' body image affect their own breastfeeding practices: A qualitative study in Ghana

\title{
Authors:
}

Angela Kwartemaa Acheampong $(\mathrm{PhD}, \mathrm{RN})^{1}$

Alhassan Sibdow Abukari $(\mathrm{PhD}(\mathrm{c}), \mathrm{RN})^{1}$

\section{Authors Affiliations:}

${ }^{1}$ School of Nursing, Wisconsin International University College-Ghana

P.O Box LG, Accra Ghana

\section{Corresponding Author:}

Alhassan Sibdow Abukari (PhD(c), RN) School of Nursing, Wisconsin International University College-Ghana. P.O Box LG, Accra Ghana. Tel: 00233-245748877. E-mail: alhassan.sibdow@wiuc-ghana.edu.gh

\begin{abstract}
Background: The World Health Organization has recommended that, all infants should be breastfed for at least two years with six months of exclusive breastfeeding. This is due to the many benefits of breastfeeding to the mother, child and the nation. There is paucity of literature on the breastfeeding practices of nurses and midwives with regards to issues relating to body image. Therefore, this study explored the perspectives of breastfeeding nurses and midwives on how their body image affect their breastfeeding practices.
\end{abstract}

Methods: Qualitative exploratory descriptive design was used to conduct this study. Five focus group discussions were conducted with each group having five members after participants were 
purposively selected into the study. Data was analyzed inductively after it was audiotaped and transcribed verbatim.

Results: Three main themes emerged after data analysis which included: Body image concerns and breastfeeding, sociocultural pressures and breastfeeding and coping strategies. Participants were of the view that, they had concerns with regards to weight gain due to the need to eat adequately in order to lactate. To participants, those concerns and pressures negatively affect their breastfeeding practices. These body image concerns are fueled by sociocultural pressures such as negative comments from loved ones and social media. They coped with self-motivation and the love they have for their children.

Conclusion: It is apparent that, breastfeeding health professionals need support in order to successfully breastfeed their infants till the stipulated time frame.

Keywords: Nurses and midwives, breastfeeding, body image and breastfeeding, body image concerns, Ghana, sociocultural pressures and breastfeeding.

\section{Background}

The World Health Organization espouses that, breastfeeding should be given exclusively to infants for six months and this should be followed immediately with complementary breastfeeding till the infant is two years old [1]. This directive is due to the myriad of documented positive health outcomes of breastfeeding for the mother, child and the society as a whole [2-12]. If breastfeeding is practiced as recommended between zero and twenty three months, it has the potential to prevent over eight hundred thousand deaths among children under five globally [13]. Regardless of the numerous benefits of breastfeeding, 38\% of infants are exclusively breastfed for six months 
globally and the figure is around $31 \%$ in West and Central Africa [14]. In Ghana, exclusive breastfeeding rate has dropped considerably by $11 \%$ from $63 \%$ in 2008 to $52 \%$ in 2014 [15].

Body image concerns have been documented widely in literature as one of the reasons why most women shorten the breastfeeding duration of their infants [16-26]. Negative body image concerns among breastfeeding mothers lead to depressive symptoms such as constant feelings of sadness, general disinterest in one's surroundings, loss of appetite and reduced self-esteem which eventually lead to shorter than recommended breastfeeding duration [23, 25, 27, 28]. The body image concerns also lead to eating disorders in breastfeeding mothers during the postpartum period that can lead to obesity and gross overweight $[16,19,21,26,29]$. This obesity and overweight concerns make breastfeeding mothers feel fat and unattractive and such negative feelings about themselves lead to the early cessation of breastfeeding $[18,22,26]$. During pregnancy, some mothers intend not to breastfeed their infants after delivery due to issues relating to excess weight gain during pregnancy $[17,30]$. This is much more prevalent when pregnant women are unable to appreciate the changes that occurs in the female body during pregnancy [17].

On the other hand, there are some few breastfeeding mothers who have been documented to view their body images with admiration when they are able to breastfeed [31, 32]. This is partly due to the fact that, breastfeeding has been reported to be responsible for weight loss in young mothers $[6,32]$.

Some breastfeeding mothers yield to sociocultural pressures to lose weight immediately after delivery [33]. Sometimes, unrealistic representation of women in the media adds on to the pressures [34-36]. The celebrities and sometimes ordinary persons depict weight lost after delivery to be automatic and very easy which leads to so much pressure on the masses to lose weight immediately after delivery $[33,35,37,38]$. On the other hand, the media can be used effectively 
as a tool for promoting, supporting and protecting breastfeeding [39]. Many of the times, the pressure is from partners, family members, colleagues and peers who may have unrealistic expectations for women to lose weight immediately after delivery [33]. Meanwhile, fathers of infants have peculiar role in supporting and promoting breastfeeding among nursing mothers [40]. This buttresses what has been documented that, breastfeeding should be considered as a public health issue that has to be tackled holistically with all persons in the society involved rather than an individual affair [41].

The World Health Organization has targeted that, by the year 2025, 50\% of all infants globally should be exclusively breastfed for six months [42]. One of the most definite reasons for nursing mothers to decide to choose breastfeeding as their infant feeding choice is the attitude of health professionals towards breastfeeding [43]. Nurses and Midwives constitute the largest proportion of health professionals. Therefore, their own breastfeeding practices may affect their advocacy techniques. Meanwhile, there is dearth of documented studies on issues relating to the breastfeeding practices of nurses and midwives in Ghana. Therefore, this study aimed at exploring the perspectives of breastfeeding nurses and midwives on how the crave to achieve the expected body shape affect their breastfeeding practices.

\section{Methods}

\section{Aim, Design and Setting}

The purpose of this study was to explore the perspectives of breastfeeding nurses and midwives on how the crave for the 'perfect' body image affect their own breastfeeding practices. The researchers used a qualitative exploratory descriptive design to achieve this purpose. This design was the most appropriate for this current study because it allowed participants to pour out their 
hearts without any restrictive answers to choose from. The study was conducted in the Greater Accra Region of Ghana. Messages were sent across different nursing and midwifery social media platforms. This attracted nurses from different hospitals across the Greater Accra Region to participate in the study. This allowed the researchers to interview breastfeeding nurses and midwives across diverse settings.

\section{Sampling and Data Collection procedures}

The inclusion criteria was used to purposively recruit twenty five nurses and midwives into the study. The inclusion criteria for this study was breastfeeding nurses and midwives with infants younger than two years old and voluntarily. Soft copies of an information sheet that contained all the necessary information about the study was posted on different social media platforms for nurses. Interested participants contacted the research team and they were aggregated into five groups with each group having five members. The venues were agreed upon by the various participating groups for the researchers to meet them for face-to-face focus group discussions where all Covid protocols were observed. All participants spoke English during the discussions. A semi-structured interview guide which was developed specifically for this study was used to conduct and moderate the discussions. The interview guide was pilot tested among an initial group of similar characteristics as the study participants. Although the results from the pilot study was not added to the results of this study, the feedback helped the researchers to correct any ambiguous questions. The researchers asked open ended, non-judgmental questions that allowed free expressions by the participants. Discussions were conducted in serene, quiet venues that started with group rules that allowed sustained and active interactions among group members. The researchers used probes to elicit thick data from participants. Each group discussion lasted around 
hundred and ten minutes. Data saturation, where no new information was obtained was reached on the fifth group. Data were audiotaped and transcribed verbatim.

\section{Data Analysis}

Data analysis and verbatim transcription were done concurrently. This ensured that, emerging themes and sub-themes were further probed. Firstly, data cleaning was performed to remove all identifiable names. Content analysis was done by following the steps that have been outlined by Padgett [44]. To understand the meaning of participants' perspectives, the transcripts were read severally before words and phrases were attached to sentences (coding). The codes captured the meanings of what participants discussed. Common codes were aggregated to form sub-themes and sub-themes were then put together for main themes to emerge. Emerging themes were discussed by the researchers on several occasions to arrive at the final themes and this ensured that, participants' perceptions were not distorted.

\section{Trustworthiness of the study}

Member checking was done by contacting a few of the participants for clarification of certain opinions in order to keep those opinions intact. The same interview guide was used to interview and moderate all five groups during the discussions. Concurrent data collection and analysis allowed researchers to probe emerging themes and sub-themes in subsequent discussions. Field notes which were taken during data collection were used to confirm participants' perspectives. Data was transcribed from audio to text verbatim and some the verbatim quotes were used to back participants' perspectives thereby giving them a voice. 


\section{Ethical Considerations}

Ethical clearance was obtained from the Institutional Review Board of the 37 Military Hospital (37MH-IRB/NF/IPN/418/2020). For voluntary participation, participants were given a consent form to sign before they were allowed to participate in the study. Data was audiotaped with participants' permission. Participants were made aware of the fact that, voluntary participation meant that, they could withdraw from the study at any time without any repercussions. Anonymity was ensured by representing participants with codes.

\section{Results}

\section{Demographic data}

Twenty five (25) health professionals were recruited into the study. Sixteen (16) of them were general nurses, five (5) were midwives and four (4) were community Health Nurses. They were all breastfeeding mothers, married and had infants under two years of age. Their work experience ranged between one (1) year and ten (10) years. All participants were aged between 26 years and 35 years.

\section{Themes and sub-themes}

Three main themes emerged from the data after analysis and they included: Body image concerns and breastfeeding, sociocultural pressures and breastfeeding and coping strategies.

\section{Body image concerns and breastfeeding}

This major theme describes the various concerns shared by breastfeeding nurses and midwives concerning their body shape and image. Three sub-themes what aggregated to form this major 
theme. The sub-themes include: Concerns about generalized weight gain and breastfeeding, sagging breasts and breastfeeding and finally, concerns about abdomen and breastfeeding.

\section{Generalized weight gain and breastfeeding}

Participants lamented about how they have gained weight in all parts of their body. They attributed this generalized weight gain to the fact that they had to eat extra food in order to lactate properly. Most of the women narrated that, due to the excessive weight gain, they have switched to strict dieting regimen which has reduced their ability to produce enough breastmilk for their infants. Some of them said that, they would not practice breastfeeding till the stipulated time frame due to weight gain concerns which was preventing them from achieving their desired body image.

“...sometimes I want to have that figure...flat tummy and big back, chest out a little. I was like that oo but breastfeeding makes me eat so I'm unable to maintain my body shape.... My whole body has increased in size. I really crave for that perfect shape. It would be difficult to practice exclusive breastfeeding for six months and continue with complementary till two years because of that.” FG5B “...for me, after giving birth my weight has doubled and sometimes, I become very worried. ... to produce enough milk, I used to eat a lot. ... inwardly I complain a lot. I am alarmed. For now, in fact I am worried deep down, I just want to lose weight and come back to my normal self. Because of that, I am on a strict diet which has negatively affected my breastmilk flow." FG4D "I keep gaining weight on all parts of my body as I eat a lot in order to get enough breastmilk for my baby which worries me a lot. Because of that, there is no way I am going to breastfeed till the recommended period.” FG1D

On the other hand, a few of the participants were optimistic about not getting worried about their current situation with the hope of restoration later. 
"I didn't get sad about it, I saw it as a normal thing as a human being once you are a woman you will pass through that stage and as the children are growing you won't eat like the way you eating and that body image will be restored." FG1C

\section{Sagging breast and breastfeeding}

Some participants narrated that, due to their sagging breast as a result of breastfeeding, they would not be able to breastfeed till the stipulated time frame.

"I will not continue to breastfeed my child till two years because my breast would sag." FG5E “Sometimes, it affects me, last time I stood in front of a mirror and asked myself 'is that me?', my breast has totally sagged and sometimes I feel sad. How the shape is, the color, in fact everything has changed about the breast. I cannot breastfeed for that long" FG1D

\section{Concerns about abdomen and breastfeeding.}

Some participants complained about abdominal size and how that makes it difficult for them to have the perfect feminine body shape. They then attributed their intention not to breastfeed till the recommended period to this concern.

"After delivery, apart from the stretch marks on my abdomen, the abdomen has turned into a certain funny shape because I cannot be on a strict diet due to breastfeeding. It has become big and not every dress I wear fits... If I wear fitting dresses, my top part looks bigger than my down part which should not be the case. A woman must have a perfect feminine shape. Sometimes I look in the mirror and my stomach is bigger than my back. It would be difficult to breastfeed for the recommended period due to that." $\mathbf{F G 5 A}$ If this girl is going to breastfeed till the stipulated time frame by WHO, then my abdomen is going to look like something else. It would be difficult." FG3A 


\section{Sociocultural pressures and breastfeeding}

In this main theme, participants described how the opinions of individuals in their lives and the pressure on social media influence their body image concerns. The following sub-themes were grouped to form this major theme: husbands, other persons and social media.

\section{Husbands}

Most participants reported that, negative comments about their body shapes from their husbands were disturbing. This gave them pressure to lose weight in order to feel accepted by their partners. Such pressures have led them to undergo strict dieting regimen which affects their ability to produce enough breastmilk for their infants.

"Sometimes, my husband makes derogatory comments that "your breast is finished, everything is gone. Your breast used to be very nice but now, the baby has scattered everything" and sometimes, these comments get to me. Now, because of that, I am on a strict diet and the breastmilk flow has reduced"FG1D "I was very slim; with my first baby my weight did not change. But with my second baby I put on weight and my husband has been complaining. He will tell me that, he does not like fat women and that, if he wanted one, he would have married one. I become uncomfortable anytime he says that and that makes it difficult for me to continue breastfeeding since breastfeeding makes

me eat." FG4E "Yes, the pressure from my husband to lose weight and get the perfect female shape is too much. He makes comments like "you are fat and your tommy is growing big and won't you do anything about it?" and because of those comments, I will not breastfeed till the recommended period because I have to diet. FG3C 


\section{Other persons}

The pressure to lose weight and get into shape is also given by other persons in the lives of the nursing mothers. These other persons are mostly neighbors, colleagues and other family members. They s

"One day, when we went outside, a neighbor saw me and said, "When you're pregnant, you're very fat, after delivery too you 're fat" and I said, “Are you sure? I think I'm growing lean rather". And she said, "no...no...no you've grown too fat; it's not nice” Because of that comment, I'm dieting and I will not breastfeed them (her twins) too much too." FG5C "When I started work and I went to my mother's place, everybody was just complaining, my dad and my aunty. Even just last three days my aunty saw me for the first time since I gave birth and exclaimed! "What is this? Please watch your tommy”. It can be disturbing. It makes me watch my diet critically and the milk does not flow well due to that." FG2B They (neighbors and colleagues) keep on complaining saying "an army nurse and you are growing big like this because of delivery and breastfeeding. You are eating too much and look at your tommy, look at how nicely you used to be in your uniform, now can you be in your uniform?" So, those comments make me angry and mostly when I become annoyed too much my breast milk does not flow. ” FG5B

Conversely, there were a few participants who voiced out that, they also get such negative comments about their looks but they tried not to allow such comments to get to them in any way.

"They do make comments like your tommy is becoming big and now you look ugly. Someone told me that those days you used to look nice than this. So, I was like really! I do not allow negative comments to affect me. I belief in myself and that is all. "FG2A 


\section{Social Media}

The new way of life or culture which has now come to live with us in the form of social media was also blamed by the participants for causing their body image concerns. A few participants narrated that, the before and after pictures of celebrities and other ordinary people after pregnancy and delivery has a way of sometimes getting to them. In the process of admiring such pictures, they tend to watch their diet thereby leading to low production of milk.

"Social media is now a way of life and sometimes, the before and after pictures which are posted by some celebrities and other people has a way of getting to me. Anytime I see such pictures, I also attempt to watch what I eat which affect my milk flow." FG3D "Before and after pictures of nursing mothers on Instagram and Facebook sometimes make me reduce my food intake which also affects the amount of breastmilk I produce." FG1E

A few participants were of the fact that, social media is deceptive and that all those before and after pictures were unrealistic and untrue. Besides, those people go for surgeries and then later pretend that, they lost all the weight through exercise and dieting.

"You should know that, there are surgeries that are done by all those people on social media with unrealistic photos for their before and after photoshoots. But they won't come out to tell you that they have done surgeries. Therefore, I don't allow them to get to me"FG1B

\section{Coping strategies}

This main theme describes how participants manage to cope with their body image concerns. Selfmotivation and children were the two sub-theme that emerged from the data to aggregate to form this major theme 


\section{Self-motivation}

Although most participants complained about their body image due to pregnancy, delivery and breastfeeding, they coped by encouraging themselves that, this period was a short phase which was bound to pass. They did this with the hope that, after breastfeeding, they would exercise and get back to their desired shape.

"I encourage myself that, when am done with breastfeeding all my children, I will have to exercise more and reduce my intake of food, that's what I use to encourage myself." FG1D I cannot go out; I have to be breastfeeding baby at night. My friends will call me for parties at night, but I cannot go out. It was really disturbing me, but I have come to realized that it still part of life. It is a stage and I will get out of it eventually.FG5E

\section{Children}

Children were the source of hope for the breastfeeding mothers. Although most of the participants had complains about their body shapes, the sight of their children made them forget all the concerns they had about their looks as narrated bellow:

"Sometimes when I look at my baby, I get comforted that, my body shape may destroy because of the obligation to eat in order to produce enough breastmilk but my child deserves it." FG2C “I wish my body image could return to what it used to be but what I have in mind is my child first I just have to breastfeed my child and forget about my body image although I'm not comfortable with the way I look." FG1C "My uncle will pick phone and call me complaining that I should watch my tummy if not I cannot wear my nursing uniform. At first, I felt really bad, but later anytime I watch my baby I become motivated. So, gradually, I am overcoming their comments."

\section{FG5A}




\section{Discussion}

With regards to body image concerns, breastfeeding nurses and midwives complained about sagging breasts, size and shape of their abdomens and finally their general weight gains. Due to those body image concerns, participants reported their intentions not to follow the period of breastfeeding as recommended by the World Health Organization. Issues about body image concerns among pregnant and breastfeeding mothers which leads to shortening of breastfeeding duration have been reported extensively in literature [16-25]. In addition, intention to initiate and continue breastfeeding are all reported to be less once there are body image concerns[45]. Although that of breastfeeding health professionals as reported in this current study is difficult to find. The question is "Who takes care of the caretaker?" Perhaps, society has assumed that, once health professionals have extensive fore knowledge about the health benefits of breastfeeding, they would automatically practice it without any of the biopsychosocial concerns. But they are also human with the same needs as the rest of us. Therefore, efforts should be made to encourage the formation of mother clubs amongst breastfeeding health professionals so that they can encourage each other through the journey of motherhood. Encouraging each other may lead to less body image concerns which would eventually culminate in exercise regimen because positive body image has been reported to increase exercise desires and activities in post-partum women[46]. Moreover, learning something theoretically, teaching others and actually practicing it are totally different and sometimes complicated.

This current study reported sociocultural pressures that directly or indirectly influence breastfeeding health professionals. Negative and derogatory comments from husbands seemed to really have impact on the breastfeeding practices of the participants. The crucial role played by 
male partners in the initiation and prolonged breastfeeding duration has been widely reported in literature [40, 47-54]. Therefore, it would be prudent if the negative impact of their comments about their partners' body image on breastfeeding is well articulated to them. This may improve the effort to promote, support and protect breastfeeding by the World Health Organization. Meanwhile, male partners have been reported to want to be part of infant feeding if given the opportunity but they have little knowledge about it [55]. But the most effective intervention to involve fathers in breastfeeding has not yet been designed [56]. In addition, other persons in the lives of the participants were also crucial in affecting their breastfeeding practices. Anecdotally, words are indeed very powerful and if words are not used wisely, it may lead to a whole lot of psychological torture. Perhaps the words and opinions shared by the people around these breastfeeding health professionals are very dear to them especially that of their spouses. Consequently, partners should be involved at every stage of the breastfeeding to understand the impact of their opinions on the breastfeeding practices of their infants. Social media depiction of pregnant and breastfeeding women was also mentioned as one of the sources of pressures for the participants in this current study. Meanwhile, social media is also used to form support groups that has proven to promote breastfeeding [57]. Focus should therefore be shifted to use social media to form mother clubs that would support each other.

Participants coped with the challenges of body image concerns by encouraging themselves and using their children as their source of hope. To them, no matter the body image concerns they may have, having their children was more than enough for them to motivate themselves. Selfmotivation has been reported to be one of the strongest sources of motivation $[58,59]$. Perchance, self-motivation techniques should be employed by lactation specialists to motivate all 
breastfeeding mothers including breastfeeding health professionals to breastfeed successfully. In addition, Ghana should start training lactation specialists who would assist breastfeeding mothers.

\section{Conclusion}

This current study has brought to light the fact that, breastfeeding health professionals are also human after all. They also have concerns which need to be addressed in order for them to experience breastfeeding successfully. Participants had body image concerns after delivery and they attributed it to the fact that they could not be on strict diet due to breastfeeding. Participants felt pressured to lose weight and attain the ideal female body shape by their partners and persons around them. The culture of unrealistic pictures posted on social media was also getting to some of them and increased the pressure to lose weight. All these body image concerns and pressures affected their breastfeeding practices to an extent that, most of them intended not to breastfeed till the stipulated time frame. The authors recommend that, health professionals should avail themselves for breastfeeding support since anecdotally, it is mostly assumed that, because they are knowledgeable about breastfeeding benefits, they may not need any special attention. Future research should find out other issues that affect the breastfeeding practices of health professionals.

\section{Declarations}

\section{Ethics for Approval and consent to participate}

Ethical clearance was obtained from the Institutional Review Board of the 37 Military Hospital (37MH-IRB/NF/IPN/418/2020). All participants signed consent forms to voluntarily participate in this study. 


\section{Consent for publication}

Not applicable

\section{Availability of data and material}

The datasets analyzed during this current study are available from the corresponding author on reasonable request.

\section{Competing interests}

The authors declare that they have no competing interests.

\section{Funding}

No funding was received for this study.

\section{Authors' contributions}

AKA and ASA conceived the study, collected the data and analyzed it. AKA wrote the first draft of the manuscript for ASA to review.

\section{Acknowledgements}

The authors would like to candidly thank all participants who opted to be part of this study in the midst of this pandemic. In addition, the authors would like to thank all the previous authors whose works have been cited in this study. Without the foundation they built earlier, this project may not have been this successful. 


\section{References}

1. WHO: Nutrition; Exclusive breastfeeding. In. Geneva, Switzerland: WHO; 2016: Press release.

2. Bar S, Milanaik R, Adesman A: Long-term neurodevelopmental benefits of breastfeeding. Current opinion in pediatrics 2016, 28(4):559-566.

3. Binns C, Lee M, Low WY: The long-term public health benefits of breastfeeding. Asia Pacific Journal of Public Health 2016, 28(1):7-14.

4. Brahm P, Valdes V: Benefits of breastfeeding and risks associated with not breastfeeding. Rev Chil Pediatr 2017, 88(1):15-21.

5. Ciampo LAD, Ciampo IRLD: Breastfeeding and the benefits of lactation for women's health. Revista Brasileira de Ginecologia e Obstetrícia 2018, 40(6):354-359.

6. Jiang M, Gao H, Vinyes-Pares G, Yu K, Ma D, Qin X, Wang P: Association between breastfeeding duration and postpartum weight retention of lactating mothers: A meta-analysis of cohort studies. Clinical Nutrition 2018, 37(4):1224-1231.

7. Lowson K, Offer C, Watson J, McGuire B, Renfrew MJ: The economic benefits of increasing kangaroo skin-to-skin care and breastfeeding in neonatal units: analysis of a pragmatic intervention in clinical practice. International breastfeeding journal 2015, 10:11.

8. Muniz LC, Menezes AMB, Buffarini R, Wehrmeister FC, Assunção MCF: Effect of breastfeeding on bone mass from childhood to adulthood: a systematic review of the literature. International breastfeeding journal 2015, 10(1):31. 
9. Rollins NC, Bhandari N, Hajeebhoy N, Horton S, Lutter CK, Martines JC, Piwoz EG, Richter LM, Victora CG, Group TLBS: Why invest, and what it will take to improve breastfeeding practices? The lancet 2016, 387(10017):491-504.

10. Victora CG, Bahl R, Barros AJ, França GV, Horton S, Krasevec J, Murch S, Sankar MJ, Walker N, Rollins NC: Breastfeeding in the 21st century: epidemiology, mechanisms, and lifelong effect. The Lancet 2016, 387(10017):475-490.

11. Victora CG, Horta BL, de Mola CL, Quevedo L, Pinheiro RT, Gigante DP, Gonçalves H, Barros FC: Association between breastfeeding and intelligence, educational attainment, and income at 30 years of age: a prospective birth cohort study from Brazil. The Lancet Global Health 2015, 3(4):e199-e205.

12. Yan J, Liu L, Zhu Y, Huang G, Wang PP: The association between breastfeeding and childhood obesity: a meta-analysis. BMC public health 2014, 14(1):1-11.

13. W.H.O.: Nutrition: Exclusive breastfeeding. In. Geneva, Switzerland; 2016.

14. UNICEF: Infant and young child feeding. In., October 2019 edn: UNICEF; 2019.

15. UNICEF: UNICEF Ghana; Country Programme 2018-2022 Programme Strategy Note: Health and Nutrition 2017 In., October, 2017 edn. Ghana: UNICEF; 2017: 41.

16. Bigman G, Wilkinson AV, Homedes N, Pérez A: The Associations Between Breastfeeding Duration and Body Dissatisfaction, Ethnicity, and Obesity Among Mexican Women, a Cross-Sectional Study, ENSANUT 2012. Breastfeeding Medicine 2020, 15(3):147-154.

17. Brown A, Rance J, Warren L: Body image concerns during pregnancy are associated with a shorter breast feeding duration. Midwifery 2015, 31(1):80-89. 
18. de Jager E, Broadbent J, Fuller-Tyszkiewicz M, Nagle C, McPhie S, Skouteris H: A longitudinal study of the effect of psychosocial factors on exclusive breastfeeding duration. Midwifery 2015, 31(1):103-111.

19. Flores TR, Mielke GI, Wendt A, Nunes BP, Bertoldi AD: Prepregnancy weight excess and cessation of exclusive breastfeeding: A systematic review and meta-analysis. European journal of clinical nutrition 2018, 72(4):480-488.

20. Lyons S, Currie S, Peters S, Lavender T, Smith D: The association between psychological factors and breastfeeding behaviour in women with a body mass index

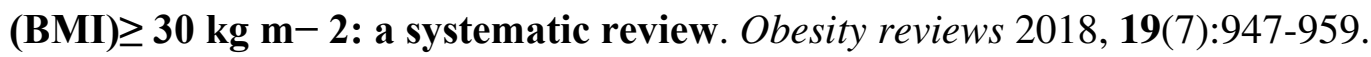

21. Rodgers RF, O'Flynn JL, Bourdeau A, Zimmerman E: A biopsychosocial model of body image, disordered eating, and breastfeeding among postpartum women. Appetite 2018, 126:163-168.

22. Shloim N, Rudolf M, Feltbower R, Hetherington M: Adjusting to motherhood. The importance of BMI in predicting maternal well-being, eating behaviour and feeding practice within a cross cultural setting. Appetite 2014, 81:261-268.

23. Silveira ML, Ertel KA, Dole N, Chasan-Taber L: The role of body image in prenatal and postpartum depression: a critical review of the literature. Archives of women's mental health 2015, 18(3):409-421.

24. Swanson V, Keely A, Denison FC: Does body image influence the relationship between body weight and breastfeeding maintenance in new mothers? British journal of health psychology 2017, 22(3):557-576. 
25. Zanardo V, Volpe F, Giustardi A, Canella A, Straface G, Soldera G: Body image in breastfeeding women with depressive symptoms: a prospective study. The Journal of Maternal-Fetal \& Neonatal Medicine 2016, 29(5):836-840.

26. Zimmerman E, Rodgers RF, O’Flynn J, Bourdeau A: Weight-related concerns as barriers to exclusive breastfeeding at 6 months. Journal of Human Lactation 2019, 35(2):284-291.

27. Hartley E, Fuller-Tyszkiewicz M, Skouteris H, Hill B: A qualitative insight into the relationship between postpartum depression and body image. Journal of reproductive and infant psychology 2020:1-13.

28. Meireles JFF, Neves CM, Carvalho PHBd, Ferreira MEC: Body image, eating attitudes, depressive symptoms, self-esteem and anxiety in pregnant women of Juiz de Fora, Minas Gerais, Brazil. Ciência \& Saúde Coletiva 2017, 22:437-445.

29. Castillo H, Santos I, Matijasevich A: Maternal pre-pregnancy BMI, gestational weight gain and breastfeeding. European journal of clinical nutrition 2016, 70(4):431-436.

30. Newby R, Davies PS: Antenatal breastfeeding intention, confidence and comfort in obese and non-obese primiparous Australian women: associations with breastfeeding duration. European journal of clinical nutrition 2016, 70(8):935-940.

31. Fern VA, Buckley E, Grogan S: Women's experiences of body image and baby feeding choices: Dealing with the pressure to be slender. British Journal of Midwifery 2014, 22(11):788-794.

32. Schalla SC, Witcomb GL, Haycraft E: Body shape and weight loss as motivators for breastfeeding initiation and continuation. International journal of environmental research and public health 2017, 14(7):754. 
33. Lovering ME, Rodgers RF, George JE, Franko DL: Exploring the tripartite influence model of body dissatisfaction in postpartum women. Body image 2018, 24:44-54.

34. Coyne SM, Liechty T, Collier KM, Sharp AD, Davis EJ, Kroff SL: The effect of media on body image in pregnant and postpartum women. Health communication 2018, 33(7):793-799.

35. Hicks S, Brown A: Higher Facebook use predicts greater body image dissatisfaction during pregnancy: The role of self-comparison. Midwifery 2016, 40:132-140.

36. Liechty T, Coyne SM, Collier KM, Sharp AD: "It's just not very realistic": perceptions of media among pregnant and postpartum women. Health communication 2018, 33(7):851-859.

37. Chae J: Interest in celebrities' post-baby bodies and Korean women's body image disturbance after childbirth. Sex roles 2014, 71(11-12):419-435.

38. Hopper KM, Aubrey JS: Bodies after babies: The impact of depictions of recently post-partum celebrities on non-pregnant women's body image. Sex Roles 2016, 74(12):24-34.

39. Marcon AR, Bieber M, Azad MB: Protecting, promoting, and supporting breastfeeding on Instagram. Maternal \& child nutrition 2019, 15(1):e12658.

40. Demontigny F, Gervais C, Larivière-Bastien D, St-Arneault K: The role of fathers during breastfeeding. Midwifery 2018, 58:6-12.

41. Brown A: Breastfeeding as a public health responsibility: A review of the evidence. Journal of Human Nutrition and Dietetics 2017, 30(6):759-770.

42. Organization WH: Global nutrition targets 2025: breastfeeding policy brief. In.: World Health Organization; 2014. 
43. Davanzo R: Controversies in breastfeeding. Frontiers in pediatrics 2018, 6:278.

44. Padgett DK: Qualitative and mixed methods in public health: SAGE publications; 2011.

45. Morley-Hewitt AG, Owen AL: A systematic review examining the association between female body image and the intention, initiation and duration of postpartum infant feeding methods (breastfeeding vs bottle-feeding). Journal of health psychology 2020, 25(2):207-226.

46. Raspovic AM, Prichard I, Yager Z, Hart LM: Mothers' experiences of the relationship between body image and exercise, 0-5 years postpartum: A qualitative study. Body Image 2020, 35:41-52.

47. Carathers J: The breastfeeding problematic: Negotiating maternal sexuality in heterosexual partnerships. In: Women's Studies International Forum: 2017: Elsevier; 2017: 71-77.

48. Davidson EL, Ollerton RL: Partner behaviours improving breastfeeding outcomes: An integrative review. Women and Birth 2020, 33(1):e15-e23.

49. Joseph FI, Earland J: A qualitative exploration of the sociocultural determinants of exclusive breastfeeding practices among rural mothers, North West Nigeria. International breastfeeding journal 2019, 14(1):1-11.

50. Lok KYW, Bai DL, Tarrant M: Family members' infant feeding preferences, maternal breastfeeding exposures and exclusive breastfeeding intentions. Midwifery 2017, 53:49-54.

51. Ogbo FA, Akombi BJ, Ahmed KY, Rwabilimbo AG, Ogbo AO, Uwaibi NE, Ezeh OK, Agho KE: Breastfeeding in the community—how can partners/fathers help? A 
systematic review. International journal of environmental research and public health 2020, 17(2):413.

52. Rabiepoor S, Khodaei A, Valizadeh R: Husbands' participation in prenatal care and breastfeeding self-efficacy in Iranian women: A randomized clinical trial. Medical journal of the Islamic Republic of Iran 2019, 33:58.

53. Tadesse K, Zelenko O, Mulugeta A, Gallegos D: Effectiveness of breastfeeding interventions delivered to fathers in low-and middle-income countries: A systematic review. Maternal \& child nutrition 2018, 14(4):e12612.

54. Young MF, Nguyen P, Kachwaha S, Tran Mai L, Ghosh S, Agrawal R, Escobar-Alegria J, Menon P, Avula R: It takes a village: an empirical analysis of how husbands, mothers-in-law, health workers, and mothers influence breastfeeding practices in Uttar Pradesh, India. Maternal \& child nutrition 2020, 16(2):e12892.

55. Alianmoghaddam N, Phibbs S, Benn C: New Zealand women talk about breastfeeding support from male family members. Breastfeeding Review 2017, 25(1):35.

56. Abbass-Dick J, Brown HK, Jackson KT, Rempel L, Dennis C-L: Perinatal breastfeeding interventions including fathers/partners: A systematic review of the literature. Midwifery 2019, 75:41-51.

57. Black R, McLaughlin M, Giles M: Women's experience of social media breastfeeding support and its impact on extended breastfeeding success: A social cognitive perspective. British journal of health psychology 2020, 25(3):754-771.

58. Cangöl E, Şahin NH: The effect of a breastfeeding motivation program maintained during pregnancy on supporting breastfeeding: a randomized controlled trial. Breastfeeding Medicine 2017, 12(4):218-226. 
59. Farwell AL: Examining the Barriers and Facilitators of Breastfeeding Duration Among Active-Duty Military Mothers. 2016. 